\title{
Determination of the Number of Ammonification Bacteria and Activity of the Ammonification Process in Soils and their Relevance for the Development of the of Soil Health Parameter
}

\author{
Semenov $\mathrm{AM}^{1,2 *}$, Khvatov $\mathrm{IL}^{3}$ and Olenin $\mathrm{AV}^{4}$ \\ ${ }^{1}$ Department of Microbiology, Biological Faculty, Russia \\ ${ }^{2}$ Russian Research Institute of Phytopathology, Russia \\ ${ }^{3}$ Department of Prostetic Dentistry, Sechenov University, Russia \\ ${ }^{4}$ Department of Macromolecular Compounds, Russia \\ *Corresponding author: Semenov AM, Department of Microbiology, Biological Faculty, Russia
}

Received: 非 January 14, 2019

Published: 㯺 January 24, 2019

\begin{abstract}
The results of daily counting of the colony forming units (CFU) number of bacteria capable of the ammonification (AMM) and activity of the AMM process using ammonium concentrations after induction of the AMM by peptone in soil samples from fallow and intensively cropped plots of gray forest soil are presented. Statistical analysis of visually observed wave-like dynamics of CFU revealed statistically significant harmonics in CFU of these soils. The harmonics of the dynamic of CFU of different soils were fairly close by their quantitative characteristics. This indicates not only the dynamic similarity, but also a comparable orderliness in the functioning of the ammonifying component in the differently used soils. The daily dynamics of the ammonium concentration in the soil samples was manifested in the form of curve accumulation of $\mathrm{NH}_{4}^{+}$in time. The presentation of the results of the dynamics of $\mathrm{NH}_{4}^{+}$in the form of subtraction differences between the subsequent concentration of $\mathrm{NH}_{4}{ }^{+}$and the previous one showed that the dynamics of daily production of $\mathrm{NH}_{4}^{+}$just like the dynamics of $\mathrm{CFU}$, has an oscillating nature. The observed differences in the dynamics of $\mathrm{NH}_{4}^{+}$in the compared soil ecosystems (SE) - the fallow and intensively cropped plots are very minor. Thus, even detailed monitoring the dynamic of AMM in SE do not allow to reveal significant differences in AMM of genetically identical but differently used soils. Therefore, the process of ammonification cannot be used to identify differences in the "nitrogen" parameters of the soil health.
\end{abstract}

Keywords: Soil; Nitrogen; Ammonification; Ammonium; Bacteria Colonies; Daily Dynamics

\section{Introduction}

The main natural processes of nitrogen inputs into the soil ecosystem (SE) are nitrogen fixation and ammonification. The latter process is often called mineralization [1]. The nitrogen fixation by bacteria is a unique biological process that has been thoroughly studied and still continues to be investigated. According to the calculation, the total annual potential nitrogen inputs into the soil ecosystem by free-living nitrogen fixers can range from tens to hundreds of kilograms per hectare. Associative nitrogen fixation is estimated to be about 10-25 kg/ha a year for soils of central Europe and up to $50-100 \mathrm{~kg} / \mathrm{ha}$ in the subtropical and tropical zones of the planet. At the same time, due to nitrogen-fixing symbionts of leguminous plants, soil enrichment with nitrogen is estimated from 60 to $300 \mathrm{~kg} / \mathrm{ha}$ per year [2,3]. A recent study of the daily dynamics of the nitrogen fixation process and the number of colonies forming units (CFU) of nitrogen fixers in cropped soil has revealed a typical wave-like dynamics of these indicators [4]. It should be noted that wave-like dynamics are always detected with long-term, daily recording of the total number of microorganisms and/or CFUs in various ecosystems $[5,6]$. However, the activity of the nitrogen fixation process in the same, but fallow soil was practically not detected, although the dynamics of CFU nitrogen fixers were clearly 
identified and as expected was wave-like. Such discrepancy shows that the nitrogen fixation is not "everyday" or "ubiquitous" process, but really an "exclusive" biological process. Therefore, the process of nitrogen fixation must be taken into account with partiality to many conditions [4].

Another important natural process of SE nitrogen supply ammonification (AMM) - is being paid less and less attention, although it takes place both in natural and agrarian ecosystems and is a "universal and perpetual engine" for maintaining nitrogen circulation in various components of terrestrial ecosystems. In soil ecosystems - the ammonification expresses the decomposition and metabolism of polymeric and monomeric nitrogen-containing substances with the release of a key substance - ammonium [7]. Small attention to the process of AMM can be explained by several reasons. High evidence of the prevalence of the process as well as a greater or smaller ability of all microorganisms to "participate" in this process, at least as a necromass. The complexity and multicomponent nature of the AMM itself, its flow both in the cell of the microorganism, and beyond. High reactivity and short "life time" of the intermediate products of the ammonification process in a free state. Significant influence on this process by both physicochemical factors and conditions, and a broad microbial diversity [8-10]. Even the concentration of such a stable final product of AMM, as ammonium, can quickly and dramatically change in the soil, and it is difficult to be quickly tracked by chemical methods. As a result, the estimated concentration in the soil is far from full, i.e. only in the form of residual quantities [11].

The literature suggests and describes with varying degree of detail mainly qualitative methods for detecting and monitoring ammonification [1,12-14]. Ammonification can be observed and detected by composting organic (plant) residues, which requires a long incubation time [15]. For the observation of AMM, incubation of moist soil with a nitrogen-containing substrate or even without it is used more often. Incubation lasts from several days to several tens of days $[16,17]$. Ammonification registration is carried out mainly at the level of quantitative registration of CFU on meatpeptone agar (MPA) and/or on starch-ammonia agar (SAA), after seeding the corresponding tenfold dilutions of the selected sample of the ammonifying substrate. Observation of the ammonification process is performed visually via changing the color of the litmus paper placed under the plug of the tube with the test sample. Of course - this is an indirect method and, in essence, it controls the dynamics of $\mathrm{pH}$ in the sample medium changes [14]. As a consequence, the results of ammonification in the overwhelming number of modern (especially Russian-language) publications are represented by the determination of only the number of CFU of bacteria attributed by the authors to ammonifiers. In this case, as a rule, the determination of CFU in the test sample is performed once, and if several times, then with a large time interval between the measurement's definitions $[18,19]$.
It should be noted that there are publications containing the dynamics of daily long-term recording of bacteria attributed by the authors to ammonifiers. In these publications, the dynamics have a pronounced oscillatory character, although the authors do not discuss these features, let alone the reasons and significance of such dynamics for a deeper understanding of the process $[20,21]$. In literature, quantitative methods for determining the ammonification process are described. The methods consist of determining the concentration of ammonification products by the amount of $\mathrm{NH}_{3}$ and $\mathrm{NH}_{4}^{+}$in the substrate that is analyzed. For example, one quantitative method for determining $\mathrm{NH}_{3}$ is titrating the acid that has absorbed $\mathrm{NH}_{3}$, released from the substrate, known as Conway's method [14]. Another method for determining $\mathrm{NH}_{4+}$ is based on a photocolorimetric evaluation of $\mathrm{NH}_{4}{ }^{+}$concentration, for example, with a Nessler reagent, usually in salt extract from the soil $[13,14,22,23]$. However, information containing a detailed description of the temporal, and especially the spatial dynamics, of the process of ammonification, and not only the number of CFU ammonifiers, is still short, shallow, and, therefore, little informative. The conclusions about the ammonification process are mainly constructed as supposedly generalizing, which does not allow using them for prognostic purposes and mathematical models, especially to apply them in the development of methods for determining soil health in relation to nitrogen [24]. Moreover, in the publications with the registration of this process in the form of a quantitative determination of one of the ammonification products - ammonium, the registration of ammonium concentration in the soil is often represented, as it is manifested, i.e. in the form of dynamics of ammonium accumulation in time. On the merits, it is a demonstration of the lack of connection between the dynamics of the ammonification process and the dynamics of the number of bacteria, which introduces delusions $[6,17,21,25]$.

The purpose of this study was to investigate the long-term daily dynamics of the number of CFUs in fallow and intensively cultivated soils and to track the daily ammonification process in these soils in terms of ammonium concentration, after initiation of the microbial community (MC) of soils by peptone application.

The tasks were set to experimentally verify:

a) The existence of wave-like dynamics in CFU ammonifiers, as is the case for any determination of the total number of CFU in the soil by seeding on solid media;

b) The dynamics of the process, designated as ammonification, which is fixed by detection of ammonium in the soil is also oscillatory, and ammonium accumulation dynamics revealed in the soil is a consequence of the "summation" of the current (initiated) ammonification process and previous ammonifying processes in the soil, leading to dynamic accumulation;

c) To determine the capabilities of the methods, traditionally 
used to determine ammonification in soils, to identify differences in the dynamics of ammonification in the soils which are genesis and landscape similar but differently used.

\section{Materials and Methods}

\section{Soil Selection and Preparation}

To determine the daily dynamics of the number of CFUs and the activity of ammonification, the same type of soil (gray forest) was used, but with a different prehistory. At the same time, it was conditionally assumed that the soil for the experiment, as an intensively used soil of a field, was designated as convention soil, and the control soil - the follow soil was meant as organic soil. Samples of the soil were selected in the village of Zaoksky, Tula region ( $1^{\text {st }}$ Rudnevsky passage, 13$)$, from the potato field of the Mittlider training center in September 2013. The soil of the field was treated according to an intensive system of agriculture with the maximum load of mineral fertilizers: N180P180K180 [26]. The duration of the use of soil in agricultural production was more than 20 years. The control soil - a fallow, was selected at a distance of about $100 \mathrm{~m}$ from the field soil. The description of the fallow area is given in [4]. The sod layer of the fallow soil (about $5 \mathrm{~cm}$ ), represented by intensive grassy vegetation was cut before the sampling. Soil samples were collected from a depth of 5-20 $\mathrm{cm}$ for fallow and 0-20 $\mathrm{cm}$ of the field, respectively. Samples were transported to the laboratory in new plastic bags, dried in a dry ventilated room at room temperature. Dried to an air-dry state, the samples were freed from the roots, sifted through a sieve with a hole's diameter of $2 \mathrm{~mm}$ and stored in an air-dry state. The initial soil $\mathrm{pH}$ is 5.5-6.0 for fallow, fields - 7.2-7.6.

\section{Setup of the Experiments and Determining the Number of Cfus}

Used nutrient medium (g/l): peptone - 10.0; $\mathrm{NaCl}$ - 5.0; ammonium ferric citrate - 0.30; agar - 15.0; yeast extract - 2.0; tap water, pH 7.0 [12]. Soil samples were simultaneously moistened to $18 \%$ and packaged in sterile vials of $5 \mathrm{~g}$. The vials were closed with SaranWrap film and incubated at $22{ }^{\circ} \mathrm{C}$. Daily prepared soil suspensions using three bottles of each sample, made the soil in sterile water in the ratio of soil: water - 5:45. The suspension were mixed on the device "Vortex" for 3 minutes. Treated with ultrasound on the device "Bransonic 12" for 5 min with an intensity according to the recommendations for the treatment of soil suspension. Soil suspensions were prepared by the method of successive tenfold dilutions. The suspensions were sown in nutrient medium in three replications by the in-depth method, introducing $1 \mathrm{ml}$ of soil suspension into the melted and cooled nutrient medium in Petri dishes. Petri dishes were incubated in a thermostat at $+28^{\circ} \mathrm{C}$ in the dark. CFU counts were made after 48 hours of incubation. The number of light colonies and separately the number of colonies staining the nutrient medium in black due to the release of $\mathrm{H}_{2} \mathrm{~S}$ (dark colonies) were taken into account. The duration of the experiment was 22 days. Experiments were performed in triplicate, repeating three times.

\section{Quantitative Determination of Ammonification Activity with Nessler's Reagent}

The soil was moistened to $40 \%$ and packaged in vials of $5 \mathrm{~g}$. Simultaneously with moistening, peptone was introduced in an amount of $40 \mu \mathrm{g} / \mathrm{g}$ of air-dry soil. The vials were incubated at +28 ${ }^{\circ} \mathrm{C}$ under a SaranWrap film in a desiccator to avoid drying out of the soil. Daily for 11 days, 3 vials from each sample were randomly used and the concentration of $\mathrm{N}^{-\mathrm{NH}_{4}}{ }^{+}$in the salt extract from the soil was determined by the colorimetric method using Nessler's reagent. Used photo colorimeter FEC-56 PM, the optical step of the cuvette was $20 \mathrm{~mm}$, the $\mathrm{pH}$ of the fallow soil is 6.0 , the field is 7.2 , at $22^{\circ}$. As the initial (zero) point, the $\mathrm{N}-\mathrm{NH}_{4}{ }^{+}$content in the soil was used before the samples were incubated. The concentration of nitrogen of ammonium in the solution was determined by the calibration curve, producing a recalculation for $100 \mathrm{~g}$ of soil according to the formula:

$$
N-N H_{4}=(a * V * 100 * k) /\left(V_{1} * 2\right),
$$

where: a - the amount of $\mathrm{NH}_{4+}$ found on the calibration scale, $\mathrm{mg} / \mathrm{ml}$; $V$ - the total volume of the extract, $\mathrm{ml} ; 100$ - the value for conversion to $100 \mathrm{~g}$ of soil; $k$ - soil hygroscopicity coefficient; $V_{1}$ the volume of the hood, taken to determine; $g$ - soil sample.

\section{Processing of the Results}

The obtained results were processed using Excel. The results of daily counts of CFU and ammonium concentrations were analyzed mathematically using the method of harmonic analysis $[6,27]$.

\section{Results}

\section{Daily CFU Dynamics}

A daily count of the CFU number of bacteria on an agar medium revealed a wave-like dynamics of the number of ammonificators both the fallow and field soil samples. The wave-like dynamics of the number of CFUs was detected, both for bacteria not deaminating sulfur-containing amino acids (light colonies), and for bacteria deaminating sulfur-containing amino acids with the formation of $\mathrm{H}_{2} \mathrm{~S}$ (dark colonies) (Figures 1 \& 2). Since the dynamics of the number of all colonies practically coincides with the dynamics of the number of only light colonies, therefore, the results of the dynamics of the total number of CFU are not presented, but the dynamics of light and dark-colored colonies are presented separately. The number of light colonies in the field soil (Figure 2) ranged from $5.21^{*} 10^{6}\left( \pm 2.63^{*} 10^{6}\right)$ to $6.17^{*} 10^{7}\left( \pm 5.24^{*} 10^{6}\right)$ per gram of soil and prevailed up to 4 times the number CFU in fallow soil: from $3.44^{*} 10^{5}\left( \pm 3.81^{*} 10^{5}\right)$ to $1.61 * 10^{7}\left( \pm 3.72^{*} 10^{6}\right)$ CFU per $g$ of soil (Figure 1). The number of light CFUs (Figure $1 \mathrm{~A} \& 2 \mathrm{~A}$ ), in general, is more than an order of magnitude greater than at the maximum points, the number of dark-colored CFU is $1.63^{*} 10^{6}\left( \pm 1.02^{*} 10^{5}\right)$ in both the soil of the field and the deposit of $7.28 * 10^{5}\left( \pm 3.00^{*} 10^{5}\right)$ (Figures 1B \& 2B). 


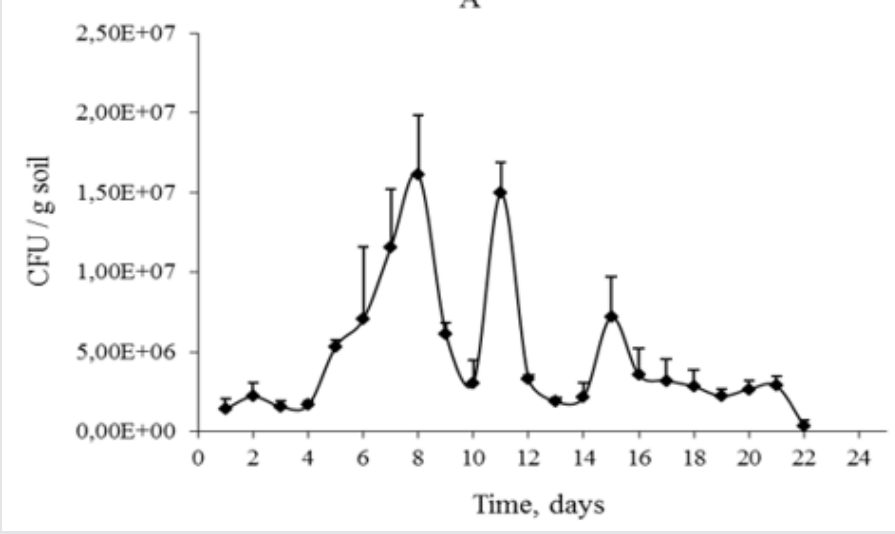

B

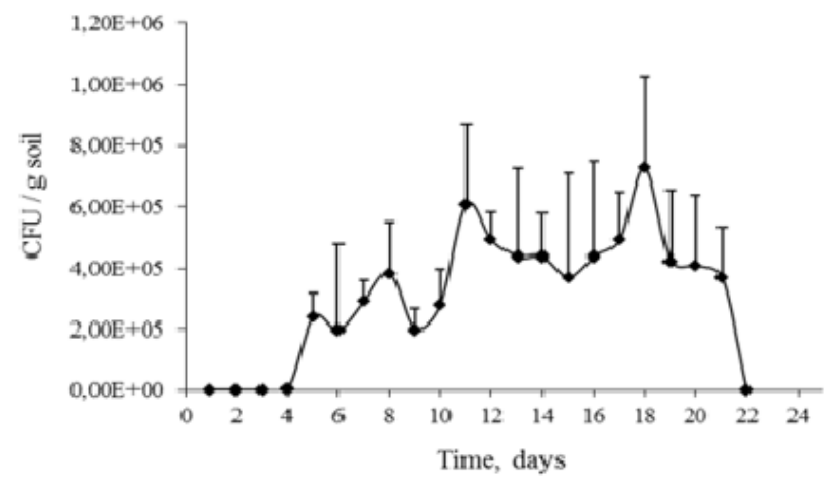

Figure 1: Daily dynamics of the CFU number of ammonification bacteria in the follow soil. A - the colonies do not produce H2S (light colonies), B - the colonies forming $\mathrm{H}_{2} \mathrm{~S}$ (dark-colored).
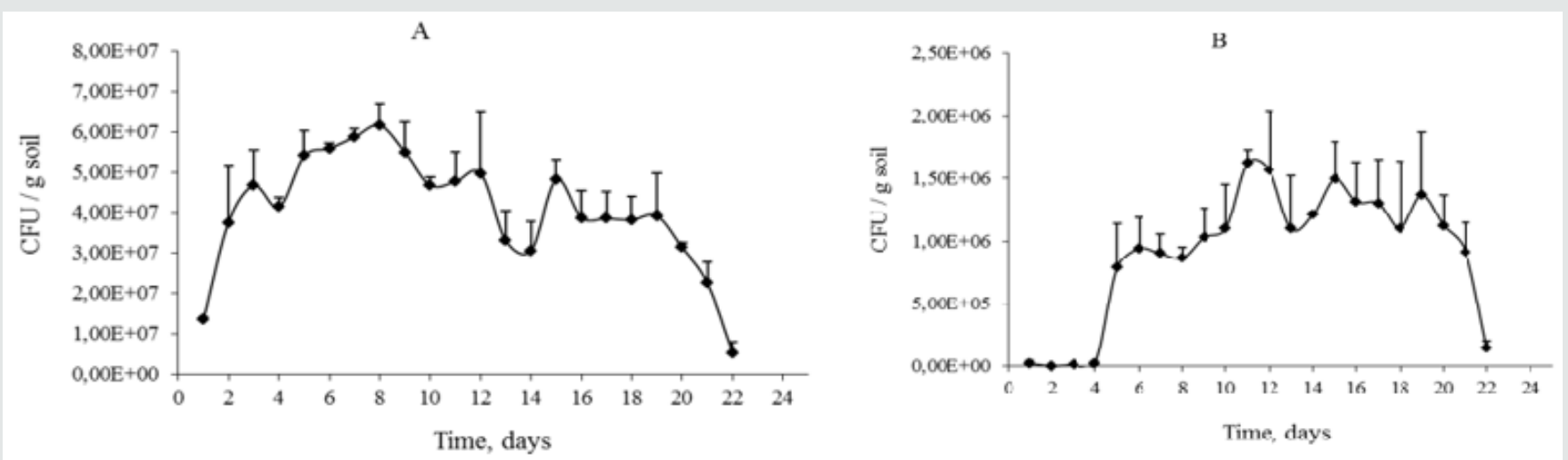

Figure 2: Daily dynamics of the CFU number of ammonificators in the field soil. A - the colonies not producing $\mathrm{H}_{2} \mathrm{~S}$. B - the colonies forming $\mathrm{H}_{2} \mathrm{~S}$.

The dynamics of CFU, both light and dark-colored colonies, of the fallow soil visually differed from the dynamics of the CFU field soil. With a daily count of CFU fallow soil, for both light and dark colors, an initial four-day lag period was observed, and the peaks, especially light colonies, and even dark colors, had more pronounced amplitudes than in the field soil. When taking into account the CFU of the field soil, the lag-period was revealed only for dark-colored colonies, and the amplitudes of oscillations of both light and dark-colored colonies were more smoothed. In the dynamics of light CFU of follow soil, there were three clear peaks at $8,11,15$ days and a less pronounced fourth peak at 21 days, for light CFU of field soil there are also four distinct peaks at 3, 8, 12, and 15 days. In the dynamics of dark-colored CFU follow soil, there were three clear peaks at 8,11 , and 18 days and with more significant "deviations" from the mean values of each point. For dark-colored CFU fields, four peaks can be distinguished, with peaks at $6,11,15$, and 19 days.

\section{Harmonic Analysis of the Dynamics of CFU}

A harmonic analysis of the results of the daily dynamics of the number of CFUs of ammonificators revealed statistically significant wave-like oscillations in the form of harmonics in both soils (Table 1). Both in fallow and in the field soils, by harmonic analysis of the dynamics of light CFUs, one fifth order harmonic was identified. In the dynamics of dark-colored CFUs (forming H2S), also one harmonic was detected, but for the fallow soil it was third-order harmonic, and for the field - only the first. The amplitude of oscillations of the CFU number of light colonies in the field soil was only 3 times higher than the amplitude of oscillations in the fallow soil, i.e. they are close, and the period, phase and frequency of oscillations are simply equal (Table 1). The amplitude of oscillations of darkcolonies in the field soil also exceeds (2.6 times) the amplitude of oscillations in the fallow soil, and the phase, period, and frequency of the oscillations of dark colonies for the samples of the fallow and field soils differ more (Figure 3).

\section{Daily Dynamics of Ammonification Activity}

Daily determination of the amount of $\mathrm{N}-\mathrm{NH}_{4+}$ by the method described above, in the soil's samples since the enrichment of them by peptone, a constant increase of the concentration of $\mathrm{N}-\mathrm{NH}_{4}{ }^{+}$in the fallow and field soils revealed. The accumulative increase in ammonium in both soils lasted without recessions until 


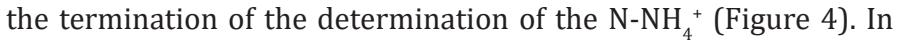
the samples of field soil, a somewhat more intense accumulation of $\mathrm{N}-\mathrm{NH}_{4}^{+}$was noted. Over time, the concentrations of $\mathrm{N}-\mathrm{NH}_{4}{ }^{+}$ accumulation converged closer in different soils and on the $11^{\text {th }}$ day of the experiment they became equal, that is, the concentration

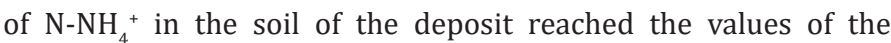

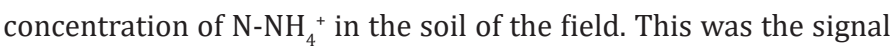
for the completion of the experiment (Figure 4).
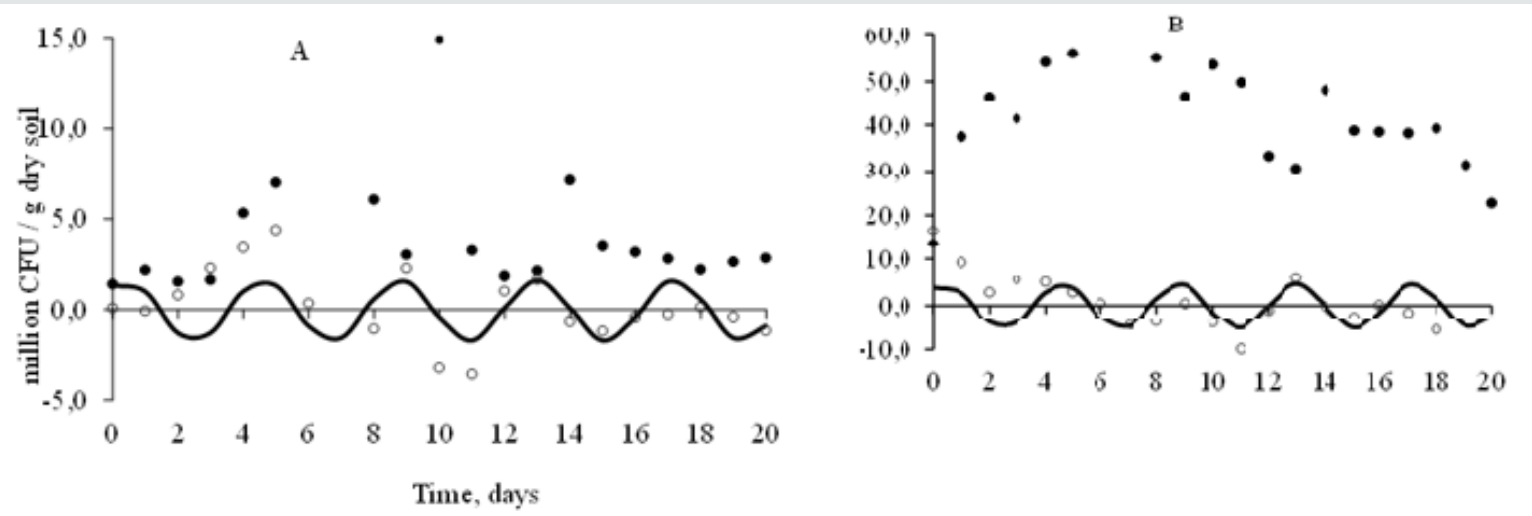

Figure 3: The harmonic analysis of the CFU numbers of ammonifiers (after filtering and smoothing) that do not form $\mathrm{H}_{2} \mathrm{~S}$. A - follow soil, B - field soil. - - experimental data; ○ - smoothed data; - - harmonics. ("Visibility" of negative values (the numbers of CFU below zero) on the graphs of harmonic analysis of ammonifiers appears due to the use of statistical operations of "filtering" and "smoothing", and therefore the locations of the number of CFU of the experimental series are graphically distributed above and below zero).

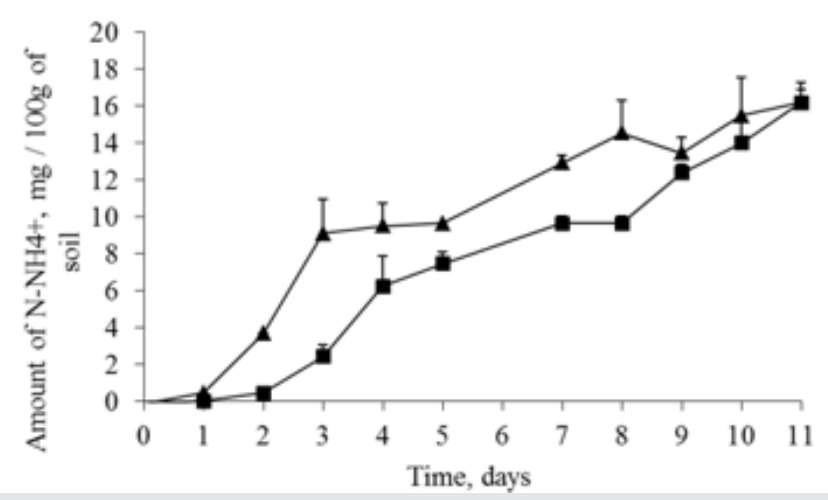

Figure 4: Dynamics of accumulation of ${\mathrm{N}-\mathrm{NH}_{4+}}_{4}$ in two soils. - - follow soil; $\boldsymbol{\Delta}$ - field soil.

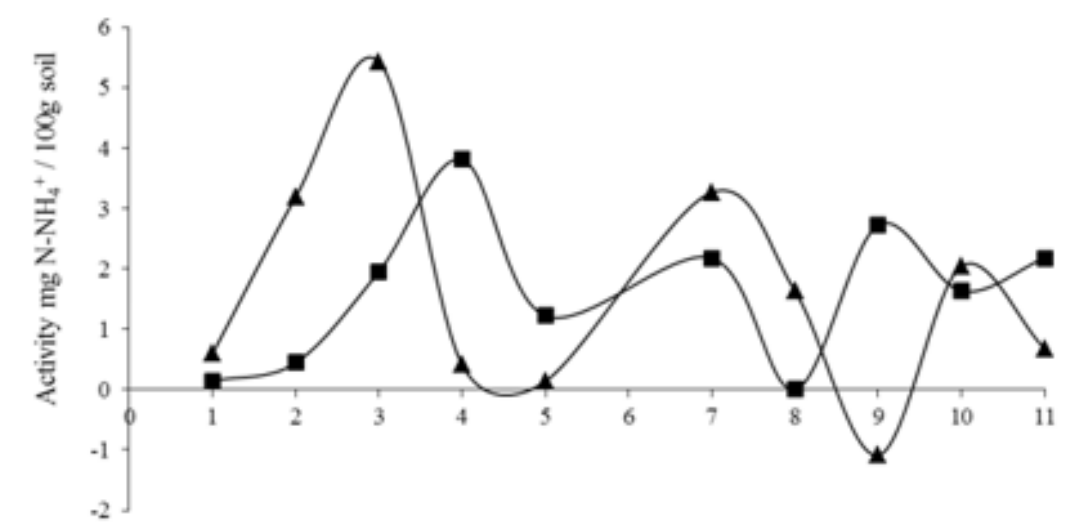

Time, days

Figure 5: Dynamics of daily activity of the formation of $\mathrm{N}_{-} \mathrm{NH}_{4}^{+}$in two soils; $\boldsymbol{\square}$ - follow soil; $\boldsymbol{\Delta}$ - field soil. 
Table 1: Characteristics of significant at the level of 0.1 harmonics of the dynamics of CFU of ammonifiers, identified after applying the filter of first differences and smoothing.

\begin{tabular}{|c|c|c|c|c|c|c|c|c|c|}
\hline Variable & $\begin{array}{c}\text { Harmonic } \\
\text { number }\end{array}$ & $\begin{array}{c}\text { Amplitude } \\
\text { (CFU/g dry soil) }\end{array}$ & $\begin{array}{l}\text { Phase } \\
\text { (day) }\end{array}$ & $\begin{array}{l}\text { Period } \\
\text { (day) }\end{array}$ & $\begin{array}{l}\text { Frequency } \\
\text { (day-1) }\end{array}$ & $\begin{array}{c}\text { Contribution to } \\
\text { variance, }(\%)\end{array}$ & F-calculated & $\begin{array}{c}\text { F-tabul for } \\
\text { significance level } 0.1\end{array}$ & $\mathbf{n}$ \\
\hline 1 & 2 & 3 & 4 & 5 & 6 & 7 & 8 & 9 & 10 \\
\hline \multicolumn{10}{|c|}{ Fallow soil: } \\
\hline $\begin{array}{l}\text { not forming } \\
\mathrm{H}_{2} \mathrm{~S}\end{array}$ & 5 & $1,68 \mathrm{E}+06$ & 0,39 & 4,2 & 0,2381 & 28,2 & 2,82 & 2,59 & 21 \\
\hline forming $\mathrm{H}_{2} \mathrm{~S}$ & 3 & $6,18 \mathrm{E}+04$ & 1,74 & 7,0 & 0,1429 & 27,3 & 2,73 & 2,59 & 21 \\
\hline \multicolumn{10}{|c|}{ Field soil: } \\
\hline $\begin{array}{c}\text { not forming } \\
\mathrm{H}_{2} \mathrm{~S}\end{array}$ & 5 & $5,08 \mathrm{E}+06$ & 0,39 & 4,2 & 0,2381 & 27,2 & 2,72 & 2,59 & 21 \\
\hline forming $\mathrm{H}_{2} \mathrm{~S}$ & 1 & $1,58 \mathrm{E}+05$ & 6,48 & 21,0 & 0,0476 & 29,0 & 2,90 & 2,59 & 21 \\
\hline
\end{tabular}

The process of ammonification, especially in the conditions of our experiments, is purely microbiological. The dynamics of CFUs of ammonificators was oscillatory, wave-like. The dynamics of known microbiological exometabolites, primarily gaseous, such as $\mathrm{CO}_{2}, \mathrm{~N}_{2} \mathrm{O}$ and even $\mathrm{CH}_{4}$, as well as the growth dynamics of microbial biomass, are wave-like, which has been shown many times $[21,28,29,5,6]$. Even the process of nitrogen fixation was truly wave-like [4]. Therefore, it was logical to expect that the production of $\mathrm{N}_{-} \mathrm{NH}_{4}^{+}$ into the soil system would also be uneven, oscillatory. However, the experimental facts which had published by different authors earlier demonstrated on the graphs the cumulative dynamics of $\mathrm{N}-\mathrm{NH}_{4}{ }^{+}$if simply recording the obtained data on the concentrations of $\mathrm{N}-\mathrm{NH}_{4}^{+}$ which were found. In order to identify ammonifiers daily produced concentrations of $\mathrm{N}-\mathrm{NH}_{4}^{+}$, the graphical results obtained by means of the subtraction of the previous day data $\mathrm{N}^{-\mathrm{NH}_{4+}}$ from the following day data, i.e. the rate of ammonium production per day, are presented (differential results!) (Figure 5). Indeed, the uneven activity of the $\mathrm{N}^{-\mathrm{NH}_{4}}{ }^{+}$formation per day was revealed, and the daily dynamics of $\mathrm{N}-\mathrm{NH}_{4}{ }^{+}$was oscillatory (Figure 5). Thus, the wave-like dynamics of $\mathrm{N}-\mathrm{NH}_{4}{ }^{+}$production by ammonifiers in soil with three peaks was detected. One peak generated 3-4 days (Figure 5).

\section{Discussion}

The daily dynamics of CFU of bacteria on such media, which researchers always use to account for ammonifiers, is wave-like. Such dynamics were expected. It is already known that daily, longterm counting of both CFU and direct microscopic counting of microbial cells, especially in natural ecosystems, always reveals wave-like dynamics microorganisms, which corresponds to one of the laws of growth and existence of biological populations $[6,30]$. The four-day "lag-period" in the dynamics of light colonies of ammonificators from the fallow soils, apparently, is due to the fact that in the MC of the natural ecosystem by the environment were "selected" such populations, which correspond to the K-strategy concept. Physiologically this is due to the consequence of the adaptation of bacteria to the new substrate. The same reason explains the presence of "lag-period" in the growth of dark colonies from all soils. In the MC of the field soil, r-strategists apparently prevail. In the environmental aspect, the differences in the dynamics of AMM populations in the compared soils can be interpreted as a "quieter" response to the disturbing of the MC fallow soil than MC of field soil. This has already been observed for soil relevant to "organic" and "convention system" systems [31].

Harmonic analysis allowed more clearly and convincingly identify the existing similarities and differences between the dynamics of CFU of ammonification of the fallow and field soil. Similarities in the harmonics order indicate that in the fallow and field soils bacterial communities mainly inhabit with similar growth values (periods and frequencies), and also, it can be assumed, with the same functional characteristics (Table 1). Similar values were also obtained when estimating the contribution of harmonics to the dispersion; values are not high. At the same time, the total contribution of all harmonics to the dispersion, both for the fallow and the field soil (55 - 56\%), is equal for the contribution to the dispersion of the harmonics of the light colonies and the dark ones. The number of light colonies has exceeded the number of dark ones by one or even two orders of magnitude, but statistically significant harmonics were found only at a level of 0.1 . It indicates that many different bacteria with ammonifying abilities in these areas inhabit and function, but "un-harmonically", i.e. not as a statistical majority. The reasons for the wave-like dynamics of CFU are the alteration of the phases of growth and dying of bacterial cells in time. Separate accounting of two types of colonies: light and dark CFU, is also a clear confirmation that many other bacteria capable in the soil to ammonification, thereby confirming once again the "variety of ammonificators".

The results of the dynamics of ammonium production per day were also subjected to harmonic analysis (Figure 5). However, the presence of significant harmonics even at a statistical level of 0.1 was not detected. This may be due to several reasons. The number of analyzed values is too short, however, for the harmonic analysis, the values of deviations from the "mean" are primarily important. A more objective reason for this is that not the dynamics of the 
biological objects themselves were analyzed, as the results of their growth and dying off or their immediate metabolites, but the "indirect" metabolites $\left(\mathrm{NH}_{4}^{+}\right)$that were obtained after their chemical transformations outside the biological object were analyzed. The

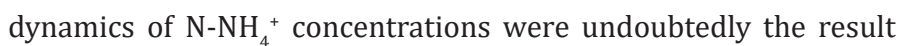
of the chemical transformation of $\mathrm{NH}_{3}$ to $\mathrm{NH}_{4}{ }^{+}$in the environment (soil), but the soil always contains some amount of $\mathrm{NH}_{4}^{+}$. Therefore, it is quite obvious that the conversion of $\mathrm{NH}_{3}$ to $\mathrm{NH}_{4}^{+}$in the soil may not be equivalent. The rate of ammonification in the form of ammonium concentration in the soil, increased over 11 days from 0.04 (fallow) and 0.4 (field) to $0.16 \mathrm{mg} / \mathrm{g}$ of soil (Figure 4). In doing so, to the end of the experiment, the indicators of the ammonium concentration for the fallow and the field soil became equal, i.e. the dynamics are equivalent. Thus, the response of the MC of both soils to the same disturbing is almost the same and wave-like (Figure 5). This indicates that the MCs of these soils are always equally "ready" to the ammonification process. Based on these results, the conclusion suggests itself that even detailed dynamic results in the form of the number of CFU and the ammonification process activity do not allow to reveal significant differences between natural SE (follow soil) and intensively exploited soil.

Thus, the traditional method of determining the ammonification of SE is not sensitive enough to use it for the rapid, routine detection of differences between two genesically and landscapeclose, but radically different in exploitation soils. As a result, the ammonification as well as nitrogen fixation [4], as the processes to the influx of nitrogen into SE, due to their insufficient selectivity (sensitivity), high labour intensity and time of capacity, cannot be recommended as methods for every day, routine analytical procedure in the soil health parameter determining in relation to nitrogen. The obtained results allow us to draw another significant conclusion. Only the "dynamics" of target microorganisms and/ or their direct metabolites can be used to assess the activity of processes and use such indicators for prognostic purposes.

\section{Acknowledgement}

The authors are sincerely grateful for the help and support in organizing and conducting research: I. Bubnov, N. Emmer, M. Golichenkov, N. Kostina, V. Semenov, E. Semenova, N. Semenova, M. Umarov, V. Zelenev, N. Zinyakova, A. Yakushev.

\section{Compliance with Ethical Standards}

a) Statement on the welfare of animals: This article does not contain any studies involving animals performed by any of the authors.

\section{References}

1. Robertson GP, Groffman PM (2015) Nitrogen transformations. In Soil microbiology, ecology and biochemistry. Fourth edition. Ed. Paul E. A., Academic Press, Burlington, Massachusetts, USA, pp. 421-446.

2. Pons TL, Perreijn K, van Kessel C, Werger MJA (2007) Symbiotic nitrogen fixation in a tropical rainforest: $15 \mathrm{~N}$ natural abundance measurements supported by experimental isotopic enrichment. New Phytol 173: 154167.

3. Umarov MM, Kurakov AV, Stepanov AL (2007) Microbiological transformation of nitrogen in soil. GEOS, Moscow, pp. 138.

4. Emer NR, Semenov AM, Zelenev VV, Zinyakova NB, Kostina NV, et al. (2014) Daily dynamics of the number and activity of nitrogen-fixing bacteria in fallow and intensely cultivated soils. Eurasian Soil Sci 47(8): 801-808.

5. Semenov AM, Bubnov IA, Semenov VM, Semenova EV, Zelenev VV, et al. (2013b) Daily dynamics of bacterial numbers, CO2 emissions from soil and relationships between their wave-like fluctuations and succession of the microbial community. Eurasian Soil Sci 46(8): 869-884.

6. Zelenev VV, van Bruggen AHC, Semenov AM (2005) Short-term wavelike dynamics of bacterial populations in response to nutrient input from fresh plant residues. Microb Ecol 49(1): 83-93.

7. Schimel JP, Bennett J (2004) Nitrogen mineralization: challenges of a changing paradigm. Ecol 3(85): 591-602.

8. Jansson SL, Persson J (1982) Mineralization and immobilization of soil nitrogen. Nitrogen in agricultural soils. Number 22, Agronomy. Edd. Stevenson FJ, Madison, Wisconsin, USA, pp. 229-252.

9. Ladd JN, Jackson RB (1982) Biochemistry of ammonification. Nitrogen in agricultural soils. Number Agronomy, ed. Stevenson FJ. Madison, Wisconsin, USA, pp. 173 - 228.

10. Pereirae Silva MC, Poly F, Guillaumaud N, van Elsas JD, Salles JF (2012) Fluctuations in ammonia oxidizing communities across agricultural soils are driven by soil structure and pH. Frontiers in Microbiol 3(77): 1-22.

11. Bundy LG, Meisinger JJ (1994) Nitrogen availability indices. Methods of soil analysis. Microbiological and biochemical properties. Edd. by Bigham JM. USA, Wisconsin, Madison: Soil Science Society of America pp. 951-984.

12. Manual on Soil Microbiology and Biochemistry, by DG Zvyagintsev (1991) Moscow State Univ, Moscow, pp. 304.

13. Mineev VG, Durinina EP, Kochetavkin AV, Gomonova NF (1989) Manual on agrochemistry. Moscow: MSU Publishing House. pp. 304.

14. Segi Y (1983) Methods of soil microbiology. Moscow: Kolos, pp. 296.

15. Samtsevich SA (1974) Biodynamics of cultivated and uncultivated soil. Materials of the Sympos. Dynamics of microbiological processes in soil and factors contributing to it. Septem. 4-5, Tallinn. Editorial Board of the AS of the ESSR, pp. 30-34.

16. Slavnina TP, Pashneva GE (1976) Simulation of nitrification and ammonification processes in gray forest soil. Soil Sci 3: 35-41.

17. Tretyakova EP (1977) Effect of temperature on the processes of ammonification and nitrification in podzolic soils of the Far North. Soil Sci 6: 158-162.

18. Svistova ID, Stakhurlova LD, Eremenko MV, Bendyak AYu (2011) Biotesting long-cultivated leached chernozem of different levels of fertility. Agrochem 5: 54-59.

19. Stakhurlova LD, Svistova ID, Scheglov DI (2007) Biological activity as an indicator of fertility of chernozem in various biocenoses. Soil Sci $40(6)$ : 694-699.

20. Kutuzova RS (1979) The nature of short-term changes in the total number of soil bacteria, including ammonifiers, during the vegetative period. Microbiol 5: 906-914.

21. Cook KA, Greaves MP (1987) Natural variability in microbial activities. Pesticide effects on soil microflora. Edds; Somerville L and Greaves MP Philadelphia: Taylor \& Francis pp. 15-43.

22. Mukhortov Ya N (1978) Ammonification and nitrification processes in leached chernozem in connection with fertilizers and tillage methods in crop rotation. Agrochem 6: 12-17. 
23. Naumov NS (1983) Features of ammonification and nitrification in eroded soils. Agrochem 5: 10-14.

24. Semenov AM, Sokolov MS, Glinushkin AP, Glazko VI (2017) The health of soil ecosystem as self-maintenance and sustainable bioproductivity. Acta phytopathol. et entomol Hungarica 52: 69-81.

25. Cherobaeva AS, Stepanov AL, Kravchenko IK (2012) The influence of cold shock on the activity and composition of ammonium oxidizing microbial community in chestnut soil. Soil Science 5: 574-581.

26. Zinyakova NB, Khodzhaeva AK, Tulina AS, Semenov VM (2013) Active organic matter in gray forest soil of arable and fallow lands. Agrokhim 9: 3-14.

27. Lavrenteva EV, Semenov AM, Zelenev VV, Chzhun Yu, Semenova EV, et al. (2009) Daily dynamics of cellulase activity in arable soils depending on management practices. Eurasian Soil Science 42: 952-961.
28. Khojaeva AK, Semenov VM, Dulov LE, Semenova NA, Kuznetsova TV, et al. (2010) Diagnostics of soil biological properties in organic and traditional farming systems. Agrochem 5: 5-14.

29. Semenov VM, Kuznetsova TV, Semenov AM, Kravchenko IK (2013a) Methane emission and consumption in Russian Gray forest agricultural soil: monthly, daily and diurnal variations and effect of mineral and organic fertilization. World Appl Sci J 24(4): 528-533.

30. Turchin PV (2002) Do general laws in population ecology? J General Biol 63: 3-14.

31. Van Bruggen AHC, Semenov AM (2000) In search of biological indicators for soil health and disease suppression. Applied Soil Ecol 1: 13-24.

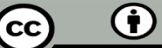

This work is licensed under Creative

Commons Attribution 4.0 License

To Submit Your Article Click Here:

Submit Article

DOI: $10.32474 /$ CIACR.2019.06.000231

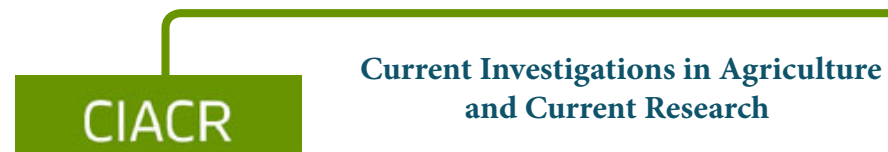

\section{Assets of Publishing with us}

- Global archiving of articles

- Immediate, unrestricted online access

- Rigorous Peer Review Process

- Authors Retain Copyrights

- Unique DOI for all articles 